\title{
Assessing the potential demand for and effectiveness of integrating STI/HIV management services with Zimbabwe National Family Planning Council's clinic-based family planning services
}

Baker Ndugga Maggwa

Ian Askew

Population Council

Hazel M.B. Dube

Caroline S. Marangwanda

Sithokozille Simba

See next page for additional authors

Follow this and additional works at: https://knowledgecommons.popcouncil.org/departments_sbsr-rh

Part of the Demography, Population, and Ecology Commons, Family, Life Course, and Society Commons, International Public Health Commons, and the Maternal and Child Health Commons How does access to this work benefit you? Let us know!

\section{Recommended Citation}

Maggwa, Baker Ndugga, lan Askew, Hazel M.B. Dube, Caroline S. Marangwanda, Sithokozille Simba, and Ahmed Latif. 1999. "Assessing the potential demand for and effectiveness of integrating STI/HIV management services with Zimbabwe National Family Planning Council's clinic-based family planning services," Africa OR/TA Project II. Harare: Population Council, University of Harare, and the Zimbabwe National Family Planning Council. 


\section{Authors}

Baker Ndugga Maggwa, lan Askew, Hazel M.B. Dube, Caroline S. Marangwanda, Sithokozille Simba, and Ahmed Latif 


\title{
Assessing the Potential Demand for and Effectiveness of Integrating STI/HIV Management Services with Zimbabwe National Family Planning Council's Clinic-based Family Planning Services
}

\author{
Maggwa Ndugga \\ Ian Askew \\ Hazel Dube \\ Caroline Marangwanda \\ Sithokozille Simba \\ Ahmed Latif
}

1999

Africa OR/TA Project II

Population Council 


\section{BACKGROUND}

HIV/AIDS is still a threat today to individual lives and national economies of many subSaharan African countries, despite many efforts and investments made by governments and international agencies to contain its spread. Besides HIV/AIDS, the region also suffers some of the highest levels of other Reproductive Tract Infections (RTIs) in the world $\begin{array}{llll}1 & 2 & 3 & 4\end{array}$. Some of these RTIs, especially those associated with genital ulcers (syphilis and chancroid), chlamydia and gonorrhea, have been proven to increase the risk of sexual transmission of HIV infection.

The control of RTIs is therefore seen not only as an important reproductive health care strategy to alleviate the immediate symptoms of infection and the long-term gynecological, obstetric and neonatal complications, but also as a key strategy in reducing the spread of HIV/AIDS. As a result, most national health care programs in the region are actively seeking cost-effective ways of implementing an RTI management program that would reduce and prevent RTIs and HIV.

To date, most emphasis has been placed on managing RTI/HIV within the so-called "high-risk" groups, such as sex workers, men and, to a lesser extent, adolescents. Encouraged by the findings of the Mwanza intervention study and by the ICPD Cairo Conference, many programs are now trying to reach a much bigger proportion of the sexually active, and thus potentially at risk, population, that is women within the reproductive age group. In particular, ways are being tested to reach this population through integrating RTI/HIV management services into existing MCH/FP programs. This approach is being pursued for a variety of reasons.

First, the levels of HIV in many sentinel antenatal clinics are already very high among women attending these clinics (in 1995, the range was $4-32.5 \%$ ). Data from the sentinel surveillance in Zimbabwe show that 30\% of antenatal women were infected with HIV in $1995^{5}$. The prevalence of the common sexually transmitted infections (gonorrhea, syphilis and trichomoniasis) are also thought to be relatively high among women

attending MCH/FP clinics in the region 678910 . A major problem, however, is the fact that there is little reliable data on these infections and the existing information shows wide variations within similar populations

Second, women attending $\mathrm{MCH} / \mathrm{FP}$ clinics constitute a larger population than those seeking special services. The vast majority of women (89-95\%) ${ }^{11}$ in the region attend clinics for antenatal care at least once during pregnancy and quite regularly thereafter for child welfare services. Over $95 \%$ of women delivering in the three years preceding the Zimbabwe Demography and Health Survey of 1994 had attended antenatal clinic at least once and $31.1 \%$ of sexually active women were using a modern contraceptive method. The survey also showed that $82 \%$ of women who were currently using a modern family planning method had obtained it from a clinic facility. 
These data show that many women utilize MCH/FP clinics and therefore could be reached with other reproductive health services through these facilities. The Zimbabwe National Family Planning Council (ZNFPC) was named as the source of the most recent family planning method by $23 \%$ of women who were currently using a modern method in 1994.

Third, the concept of providing comprehensive reproductive health services to women has received global support since the Cairo ICPD and Beijing Women's Conference. Both conferences called on programs to go beyond providing vertical services that meet specific needs to integrated services that address all aspects of human sexuality and reproductive health needs.

In its five-year plan for 1998-2002, the ZNFPC committed itself to improving its ability to provide an integrated range of reproductive health services including RTIs, HIV/AIDS and family planning. Although there are many strong reasons to support an integrated approach, there remain many unanswered questions concerning its implementation, effectiveness and cost-effectiveness. The findings from this study, undertaken by the ZNFPC with technical and financial assistance from the Population Council, provide answers to some these questions.

\section{STUDY OBJECTIVES}

The overall goal of the study was to assist the ZNFPC in obtaining information that would enable it to develop the most appropriate and effective approach to managing RTIs including HIV among its clinic clientele.

The specific objectives were:

To describe the preparedness and approach currently used by ZNFPC clinics to manage clients suspected of having an RTI.

To design interventions using findings from the first objective to improve on program preparedness to provide RTI and family planning services using an integrated approach.

To describe the characteristics and the prevalence of RTIs among family planning clients attending ZNFPC clinics.

To determine the prevalence of RTI/HIV risk factors among family planning clients attending ZNFPC clinics.

To measure the sensitivity, specificity and positive predictive values (PPV) of the approach and algorithms currently used in the syndromic management of RTIs in a family planning clinic setting. 
To predict the effect of adding risk scoring on the PPV of algorithms currently used for syndromic management of RTIs.

To determine the cost-effectiveness of different strategies for integrating RTI management services with family planning services at the ZNFPC clinics.

. To determine the acceptability and impact of using a standardized checklist in managing RTIs.

The study used a variety of methods to collect and synthesize information that the ZNFPC could use in developing an appropriate and cost-effective approach to the integration of RTI/HIV with its family planning services.

The following sections discuss the methods used to collect information and the study results specific to each of the study objectives. 


\section{PREPAREDNESS TO FACILITIES TO PROVIDE RTI SERVICES}

To describe the strategy for managing family planning clients presenting with symptoms of RTIs at the ZNFPC clinics prior to the interventions, data were collected using the Africa OR/TA Project's integration case study methodology 12. Eight clinics were selected from the 19 ZNFPC clinics (Spilhaus, Mpilo, Vengere, Gweru, Bindura, Plumtree, Chiredzi and Chinhoyi) for the baseline survey. Apart from having high client volumes, these clinics were selected to represent the different provinces in Zimbabwe.

The quality and nature of RTI and HIV services that clients received at the ZNFPC clinics was determined through observation of interactions between clients and service providers. For the baseline survey, consultations for 160 new and repeat (due for annual assessment) family planning clients with 19 providers (one doctor, 5 nurses and 13 midwives) at the 8 study clinics were observed over a five-day period.

All clients whose interactions with the service provider were observed were interviewed on completion of the consultation. The interviewer collected information on the clients' perspective of the quality of the interaction, including the information communicated on family planning and RTIs/HIV/AIDS.

Existing Service Delivery Policies and Standards manuals, client records and other reporting forms were reviewed to identify gaps, conflicting issues and requirements to facilitate the provision of RTI/HIV and $\mathrm{MCH} / \mathrm{FP}$ services using an integrated approach.

The number of clients that each member of staff was observed interacting with varied from staff to staff.

Due to the small sample sizes involved in some clinics, percentages or proportions of success are not very meaningful and can be misleading in interpreting the quality of services offered at the clinics. To overcome the problem of small sample size, the principle of Lot Quality Assurance Sampling (LQAS) ${ }^{13}$ was used to decide whether the ZNFPC static facilities were well prepared to provide integrated family planning and RTI services and whether the services offered by staff and/or clinic can be considered satisfactory 14 .

Findings from the baseline survey are presented below.

\section{Physical infrastructure}

The readiness of the physical infrastructure to support the provision of family planning and RTI services in an integrated approach was assessed using the availability of the following five items.

Working toilets for clients

Functioning water source on compound 
Functioning sources of energy

Shelter for waiting clients

Separate counseling/exam room

All the facilities in the study sample had these basic items required to provide family planning and RTI services except for one clinic that did not have a separate counseling/examination room. Using the LQAS decision rules, it was concluded that the ZNFPC facilities have the basic infrastructure required to provide RTI and family planning services using an integrated approach.

\section{Equipment}

Availability of the following basic equipment is a prerequisite for proper delivery of family planning and RTI services.
Adult weighting scale
Angle poise/gynecology
Blood pressure machines
Examination couch
Microscope
Stethoscopes

The assessment found that three of the eight study clinics did not have a microscope but all eight had the rest of the basic equipment. The current practice in Zimbabwe is to manage RTIs using a syndromic approach that does not require a microscope. Therefore, it was concluded that the ZNFPC clinics are well equipped to provide the basic family planning and RTI services using an integrated approach.

\section{Infection control}

When providing family planning and RTI services, infection control facilities should be readily available to enable the service providers to practice good infection control procedures. In this baseline survey, the availability of dustbins, sharps-disposal container, waste-disposal facilities and antiseptic lotions were used to assess readiness of facilities to practice good infection control procedures. Four of the eight health facilities included in the study did not have an incinerator or waste pit to dispose of their contaminated waste. These data suggest that the ZNFPC clinic facilities were prepared to practice infection control procedures in the clinic but are not well prepared to dispose of the waste generated through the provision of their services.

\section{Commodity logistics}

Availability of drugs for treating RTIs and contraceptives is important if ZNFPC clinics are to provide RTI/FP services. During the study, the availability of drugs recommended for the treatment of RTIs in the national guidelines was assessed. Overall, the study 
found that the ZNFPC facilities did not have in stock the drugs recommended for treating RTIs following the current algorithms. For example, 4 of the 8 study clinics did not have kanamycin, a drug recommended for the first line treatment of gonorrhea, and 7 did not have benzathine penicillin for treating syphilis. Based on these finding it was concluded that the ZNFPC facilities are not prepared to treat RTIs even if they were able to make a diagnosis. However, all the facilities had adequate stocks of contraceptives, including condoms.

\section{Quality of services provided}

During exit interviews with 157 of 160 clients whose consultation with clinic staff had been observed, the clients were asked about their perception of and satisfaction with the services they had received. The questions covered the following service delivery components.

Provision of additional services

Adequacy of consultation time

Provider listens to client's problems

Clients' freedom to ask questions

Satisfaction with provider's responses

Provider's explanation of examination results

Provider's explanation of clients' health problems

Adequacy of privacy

Provider easy to understand

Clients reported high levels of satisfaction with the services received from the facilities, with most clients reporting that they were given enough privacy during the consultations and that the provider was easy to understand and had listened to their problems. Although a few clients indicated dissatisfaction with the explanation of examination results, the clients rated the overall quality of services received high.

The policy guidelines require service providers to carry out medical examinations for all new FP clients.

A full medical examination consists of taking a medical history, measuring blood pressure and weight, performing general physical examination, a breast examination and a pelvic examination. These procedures were undertaken for most of the clients whose consultations were observed.

During the observation, service providers' skills in performing pelvic examination were assessed. Service providers' performance on pelvic examination was found to be quite satisfactory with providers passing on five out of eight items used to assess their skills on pelvic examination $^{15}$. 
Most service providers did not ask clients to pass urine before the exam, did not carry out a bimanual examination and did not take a Pap smear. These are essential components of pelvic examinations and the ZNFPC training program needs to update their staff on pelvic examinations with an emphasis on these components.

STI/HIV risk assessment has been recommended as one of the strategies for identifying clients with STIs particularly in cases where the clients are asymptomatic. Therefore, one of the key elements of an integrated approach to providing STI services in a family planning clinic is for the service providers to undertake STI/HIV risk assessment for all family planning clients.

However, it was observed during the baseline survey that only three of the 19 service providers at the eight clinics included in the survey carried out STI/HIV risk assessment during the 160 client consultations observed.

It was also observed that only 3 and 4 of the 19 service providers had discussed issues such as breastfeeding and socio-economic status, respectively, in addition to discussing family planning issues with their clients. None of the service providers discussed immunization, child growth monitoring, infertility, oral rehydration therapy or abortion with their clients.

In summary, the baseline survey showed that ZNFPC static facilities had most of the basic physical infrastructure required to provide RTI and family planning services using an integrated approach. However, the facilities lacked drugs recommended for treating RTIs and the staff were not carrying out STI/HIV risk assessment for the family planning clients. Although the ZNFPC management thought that their program was integrated, the baseline survey showed that many clients were not being provided with and/or informed about other reproductive health issues. 


\section{STEPS TAKEN TO IMPROVE PROGRAM PREPAREDNESS}

Following the baseline survey, the ZNFPC with technical and financial assistance from the Population Council, implemented the following interventions to facilitate studying the remaining specific objectives of the study.

\section{Refresher training for clinic staff and supervisors}

During the baseline survey, staff were found to be deficient in the knowledge of the syndromic approach for managing RTIs as recommended by the national RTI program. The clinic staff were following algorithms that were different from the national algorithms. To standardize the quality of RTI services provided at the three study clinics using the national algorithms, staff providing services at the three study clinics, their supervisors, trainers and program managers attended a one-week refresher course on the syndromic management of RTIs. The course was conducted using the training curriculum

and modules recommended by the National STI Program ${ }^{16}$. The staff were also trained on how to collect specimens for laboratory tests, as this was going to be a major component of the intervention study. After the course, clinic staff were now expected to follow the national algorithms for managing RTIs in their clinics.

\section{Development of a standardized checklist}

During the baseline, it was found that the clinic cards used to obtain information from clients were lacking components that would facilitate the collection of information essential for the diagnosis and management of RTIs. The forms also did not have any questions to facilitate RTI/HIV risk assessment. In addition the forms did not provide any guidance on information giving and counseling about RTIs and HIV.

During interviews with clinic staff lack of an integrated checklist to guide and remind them was cited as one of the reasons why most of them did not undertake STI/HIV risk assessment and counseling for their clients. With assistance from the Population Council, an integrated checklist (see appendix) was developed and introduced for use in the three study clinics after clinic staff were trained on its use.

\section{Negotiations to ensure drug availability}

Another problem that had been identified in the baseline survey was the lack of drugs recommended for the treatment of RTIs at the clinics. The ZNFPC management with assistance from USAID negotiated with the national STI project, World Bank and DFID to include the three study clinics in an ongoing project that supplies RTI drugs to health facilities.

The Population Council also provided funds to support the availability of other supplies required to provide family planning and RTI services. This support freed up some funds for the ZNFPC, which were then used to purchase drugs to supplement the supplies from the national STI project. Through this process, the three study clinics had access to the RTI drugs recommended by the national algorithms throughout the study period. 


\section{PREVALENCE OF REPRODUCTIVE TRACT INFECTIONS, SYMPTOMS AND SIGNS}

During the 12 months following implementation of interventions to improve program preparedness to provide RTI services using the syndromic approach, all new family planning clients, clients visiting the clinic for resupplies, clients having problems with their method, clients seeking RTI services, and repeat clients who came for their annual check-up at the three study clinics were requested to participate in the second phase of the study.

Each client was given an explanation of the study objectives, design, benefits and potential disadvantages that may result from her participation.

Those who agreed to participate in the study had a pelvic, breast and general physical examination performed. Using a standardized checklist to conduct clinical examinations (see appendix), staff looked for the presence of abdominal tenderness, rebound tenderness, vaginal or cervical discharge, ulcers in the genital area, changes in the color of the cervix and friability, adenexial masses, adenexial tenderness and uterine size.

The staff were required to use the information to make diagnosis and decide treatment, based on the current national algorithms used for the syndromic diagnosis and management of RTIs.

Specimens for RTI testing were collected from all 1634 family planning clients who consented to participate in the study and had been evaluated clinically.

During the pelvic examination, clinic staff collected high vaginal and endocervical swabs, which were used to test for gonorrhea, chlamydia, candidiasis, trichomoniasis and bacterial vaginosis. All specimens were delivered to the laboratory the same day and results made available within seven days.

All the clients, who accepted to have specimens taken for laboratory testing, were requested to return to the clinic after seven days for their results. Follow-up letters were sent to those clients who did not return for their test results within fourteen days.

During subsequent visits the women who needed treatment for RTIs or a change in their medication on the basis of laboratory test results were requested to visit the clinic where they were reviewed and treated.

The following table indicates the reproductive tract infections that were tested for, the specimens that were collected and the tests performed. 
Table 1: Laboratory Test Performed

\begin{tabular}{|l|c|}
\hline RTI & \multicolumn{1}{|c|}{ TEST } \\
\hline Gonorrhea & $\begin{array}{c}\text { Culture, Gram stain and } \\
\text { LCR }\end{array}$ \\
\hline Chlamydia & $\begin{array}{c}\text { Fluorescent, microscopy } \\
\text { and LCR }\end{array}$ \\
\hline Trichomoniasis & $\begin{array}{c}\text { In-pouch media, gram } \\
\text { stain }\end{array}$ \\
\hline Candidiasis & Gram stain and $\mathrm{KOH}$ \\
\hline Bacterial vaginosis & Gram stain and $\mathrm{KOH}$ \\
\hline
\end{tabular}

Data entry was carried out using the EpiInfo 6.02 software with matching-screen formats to the questionnaires. The double entry procedure was used for validation of data entry. Data analysis was carried out using SPSS package Version 8.0 for Windows.

Frequency distributions and univariate analysis using two by two tables were done for all the independent variables included in the history, clinical examination and risk assessment. The independent variables were assessed for significance of association with the dependent variables using crude ODDS Ratios and P-Value. The following are the findings.

\section{i) Reasons for visiting the clinic}

A total of 1634 women attending three ZNFPC clinics (Mpilo, Lister-Bulawayo and Spilhaus) between January 1998 to December 1998 consented to participate in the study. The most common reasons for visiting the clinics by the study clients were annual checkup (35.2\%) followed by re-supply of methods (26.7\%) and RTI treatment $(25.3 \%)$ (Figure1).

The distribution of reasons for visiting the clinic was greatly influenced by the criteria for entry into the study 17 and as such may not represent the general pattern of clinic visits to the ZNFPC clinics.

Twenty- three percent of the study clients visited the clinic for more than one reason. For example $46(11 \%)$ of the women whose primary reason for visiting the clinic was resupply of method also had another reason for visiting the clinic. The two most common secondary reasons were symptoms suggestive of RTI and problems with the method. 


\section{Figure 1: Reasons for visiting}

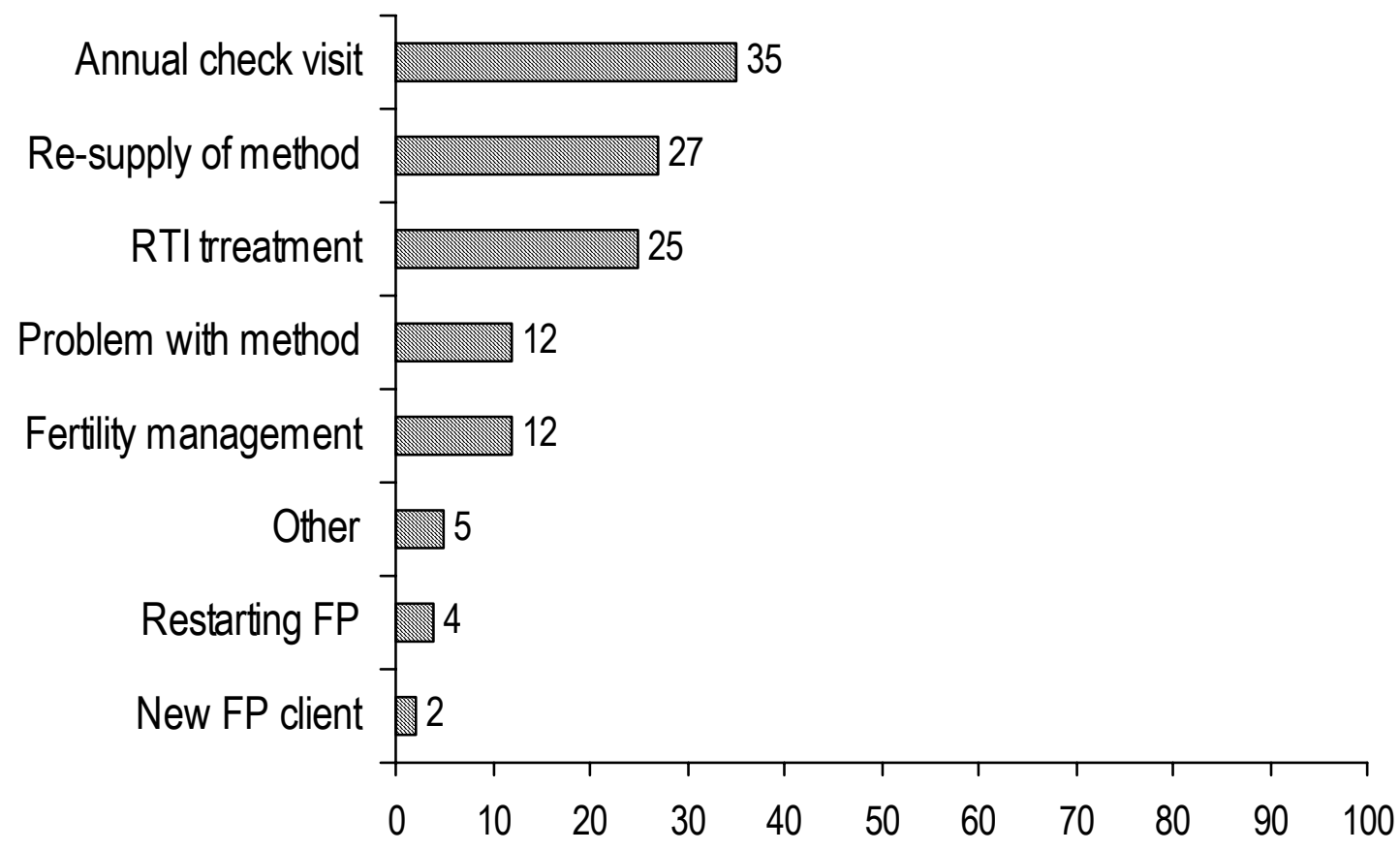

\section{ii) Socio-demographic characteristics of study clients}

The age of the study clients ranged from 15 to 66 years with a mean of 30.9 years and a median of 30.0 years. Only $2.1 \%$ of the respondents were less than 20 years, while nearly $30 \%$ were above 35 years.

The majority of the study clients had secondary school level education - this is equivalent to more than 8 years of schooling. The majority (85\%) were married and had a mean of 2.7 pregnancies and 2.0 living children. As expected the vast majority $(92 \%)$ reported a good outcome of their last pregnancy (Table 2).

\section{iii) Clinical findings and interpretation}

All women consenting to participate in the study had a detailed medical history obtained from them using a standard checklist (see Appendix 1). Women were asked if they currently had any of the symptoms associated with RTIs (Table 3). More than half of the study clients reported at least one symptom suggestive of a RTI. Multiple (more than one) RTI symptoms were reported by $35.4 \%$ of the clients.

The most commonly reported symptoms were lower abdominal pain (42.7\%) followed by pain during sexual intercourse $(18.5 \%)$ and an increase in the amount of vaginal discharge $(17.1 \%)$. 
Table 2: Socio-demographic characteristic for family planning clients

\begin{tabular}{|c|c|}
\hline CHARACTERISTICS & $\begin{array}{l}\text { PERCENT CLIENTS } \\
\qquad \mathrm{N}=1634\end{array}$ \\
\hline $\begin{array}{ll}\text { Age (in years) } \\
\bullet \quad 15-24 \\
-\quad 25-34 \\
-\quad 35+\end{array}$ & $\begin{array}{l}20.2 \\
50.5 \\
29.3\end{array}$ \\
\hline $\begin{array}{ll}\text { Highest Educational level attained } \\
\text { - } & \text { Primary } \\
\text { - } & \text { Secondary } \\
\text { - } & \text { Tertiary }\end{array}$ & $\begin{array}{c}30.0 \\
66.0 \\
3.0\end{array}$ \\
\hline $\begin{array}{ll}\text { Marital Status } \\
-\quad \text { Single } \\
-\quad & \text { Married } \\
\text { - } & \text { Widowed/divorced }\end{array}$ & $\begin{array}{c}9.3 \\
85.2 \\
5.5\end{array}$ \\
\hline $\begin{array}{l}\text { Outcome of last pregnancy } \\
\text { - Live birth } \\
\text { - Stillbirth } \\
\text { - } \\
\text { - Noortion } \\
\text { Neotal death }\end{array}$ & $\begin{array}{r}92.0 \\
1.0 \\
4.8 \\
2.2\end{array}$ \\
\hline $\begin{array}{ll}\text { Obstetric History } \\
-\quad \text { No. of pregnancies } \\
\text { - } & \text { No. of living children }\end{array}$ & $\begin{array}{l}\text { Mean }=2.67, \text { Mode }=2 \\
\text { Mean }=2.37, \text { Mode }=2\end{array}$ \\
\hline
\end{tabular}

The majority of clients seeking RTI services (92\%) and 79\% of clients seeking services due to problems with a family planning method had at least one symptom suggestive of an RTI compared with fewer than $40 \%$ for those clients seeking other family planning services.

During pelvic examination, staff noted the presence of any signs suggestive of RTIs. The majority of the women had at least one sign suggestive of a RTI (77.7\%), with $48 \%$ of them having more than one sign.

Table 4 shows that the most commonly encountered signs suggestive of RTIs were tender adenexia, (23.0\%), cervical excitation (17.6\%), discharge from the cervix (17.1\%) and white curdy discharge at the vulva (14.1\%). These data show a high prevalence of signs suggestive of RTIs among clients attending ZNFPC clinics. 
Table 3: Prevalence of RTI-related symptoms'

\begin{tabular}{|l|c|c|}
\hline \multicolumn{2}{|c|}{$\begin{array}{c}\text { Percent all study } \\
\text { clients } \\
\text { N=1634 }\end{array}$} & $\begin{array}{c}\text { Percent clients seeking } \\
\text { RTI services } \\
\mathrm{N}=410\end{array}$ \\
\hline Lower abdominal pain & 42.7 & 74.9 \\
\hline Yellow vaginal discharge & 14.7 & 30.5 \\
\hline Blood stained discharge & 8.3 & 13.2 \\
\hline Foul smelling discharge & 12.6 & 25.9 \\
\hline Increased discharge & 17.1 & 35.6 \\
\hline Post coital bleeding & 7.5 & 11.2 \\
\hline Pain during sexual intercourse & 18.5 & 33.7 \\
\hline Pain on passing urine & & 22.2 \\
\hline Genital ulcers or sores & 10.2 & 5.1 \\
\hline Genital warts & 2.6 & 4.6 \\
\hline Painful swelling in the groin & 2.5 & 1.7 \\
\hline
\end{tabular}

Clients attending clinics for problems with method (93\%), RTI treatment (96\%) and infertility $(82 \%)$ were more likely to have signs suggesting RTIs, respectively compared with those attending for annual check-up and/or resupply of methods. However, it should be noted that more than one-half of the clients attending for annual check-up and/or resupply of methods had signs suggestive of RTIs. These finding emphasize the importance of carrying out regular pelvic examination for all clients attending family planning clinics regardless of the primary reason for the visit. 
Table 4: Prevalence of clinical signs

\begin{tabular}{|c|c|}
\hline Signs by clinical procedures & $\begin{array}{l}\text { Percent all study clients } \\
N=1634\end{array}$ \\
\hline 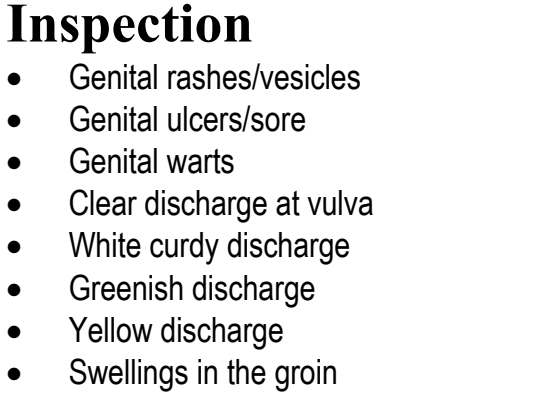 & $\begin{array}{l}0.9 \\
1.9 \\
2.0 \\
26.5 \\
14.1 \\
1.1 \\
6.6 \\
1.9\end{array}$ \\
\hline $\begin{array}{l}\text { Speculum examination } \\
\text { - } \quad \text { Warts on vaginal wall } \\
\text { - } \quad \text { White curdy discharge in vagina } \\
\text { - } \quad \text { Cervical warts/polyps } \\
\text { - } \quad \text { Discharge from cervix } \\
\text { - } \quad \text { Cervical erosion }\end{array}$ & $\begin{array}{l}1.0 \\
10.2 \\
1.2 \\
17.1 \\
7.8\end{array}$ \\
\hline $\begin{array}{l}\text { Digital examination } \\
\text { - } \quad \text { Cervical excitation } \\
\text { - } \quad \text { Tender adenexia }\end{array}$ & $\begin{array}{l}17.6 \\
23.0\end{array}$ \\
\hline
\end{tabular}

\section{iv) Prevalence of RTIs based on syndromic diagnosis}

Following recommendations by the National AIDS and STD Coordination Program (NASCOP) ${ }^{18}$ staff in all MOH and other public health facilities are supposed to use syndromic approach to diagnose and manage RTIs.

During the study period, staff were expected to use these national algorithms to diagnose and decide treatment for RTIs. Using these algorithms, $41 \%$ of the study clients were diagnosed to have at least one of the RTI syndromes. Lower abdominal pain $(27.3 \%)$ and vaginal discharge $(22.3 \%)$ were the most frequently diagnosed syndromes (Figure 2). 
Figure 2: Reproductive Tract Infection (RTI) syndromes diagnosed by clinicians (\%)

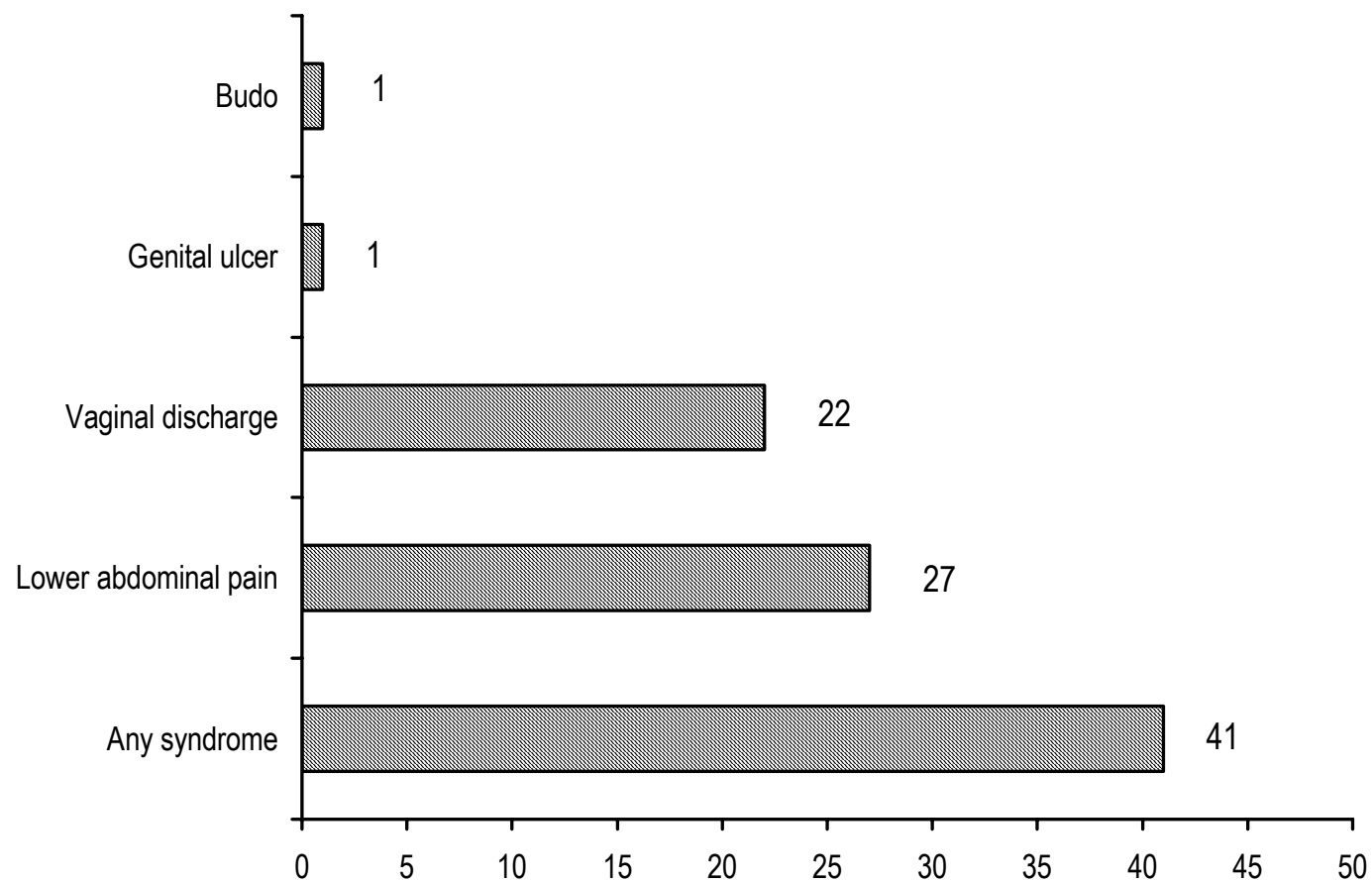

An RTI syndrome was diagnosed in $74.9 \%$ of clients whose reason for visiting the clinic was to receive RTI services. Even in this category of clients, lower abdominal pain was the most commonly diagnosed syndrome followed by vaginal discharge. These data show that clinic staff were more likely to diagnose an RTI syndrome among clients seeking RTI services.

Given that more than one-half of the study clients had at least one symptom or sign suggestive of an RTI, these data show that not all women with symptoms and/or signs were diagnosed to have a RTI syndrome.

Multiple RTI syndromes were common among the study clients. For example $25 \%$ of the 669 clients syndromically diagnosed to have a RTI had both lower abdominal pain and vaginal discharge syndromes.

\section{v) Prevalence of RTI based on laboratory tests}

A significant proportion of the study clients $(31.9 \%)$ were found to have at least one reproductive tract infection excluding syphilis on laboratory testing. Candida (17.3\%) and Clue cells $(9.0 \%)$ were the most commonly isolated organisms. The presence of these organisms is evidence for Candidiasis and Bacterial Vaginosis infections, respectively. Gonorrhea and Chlamydia, considered to be the organisms responsible for cervical infection, were less frequently isolated compared with other organisms responsible for RTIs (Table 5). 
Data on Table 5 also show that the prevalence of cervical infections was higher among clients seeking RTI services compared with all clients. However, there was no difference in the prevalence of vaginal infections between the two categories of women.

Table 5: Prevalence of reproductive tract infection detected on laboratory testing

\begin{tabular}{|l|l|l|}
\hline $\begin{array}{l}\text { Reproductive tract } \\
\text { infection }\end{array}$ & $\begin{array}{l}\text { Percent all } \\
\text { clients } \\
\text { N=1634 }\end{array}$ & $\begin{array}{l}\text { Percent clients } \\
\text { seeking RTI } \\
\text { services }\end{array}$ \\
\hline $\begin{array}{l}\text { Vaginitis } \\
\text { (Candidiasis, } \\
\text { Bacterial Vaginosis, } \\
\text { Trichomoniasis) })^{20}\end{array}$ & 28.8 & 29.3 \\
\hline Candida & 17.3 & 14.6 \\
\hline $\begin{array}{l}\text { Bacterial } \\
\text { Vaginosis }\end{array}$ & 9.0 & 8.3 \\
\hline Trichomoniasis & 4.1 & 7.1 \\
\hline $\begin{array}{l}\text { Cervicitis } \\
\text { (Chlamydia, }\end{array}$ & 4.4 & 7.1 \\
\hline $\begin{array}{l}\text { Gonorrhea) } \\
19\end{array}$ & 2.9 & 4.2 \\
\hline Chlamydia & 1.8 & 3.9 \\
\hline Gonorrhea & 10.8 & 10.0 \\
\hline Pus cells &
\end{tabular}

These data suggest that vaginal infections are much more common among women attending family planning clinics than cervical infection. The data also show that nonsexually transmitted infections are more prevalent than the sexually transmitted infections. In addition, the data show that women attending the clinics specifically for RTI services are more likely to have a sexually transmitted RTI. These findings have major implications for the treatment guidelines outlined in the existing national algorithms.

Currently, the algorithms recommend that all women with vaginal discharge be treated for cervicitis (e.g. gonorrhea and chlamydia) a relatively rare condition as data from this study have shown. These recommendations arose out of fear of the severe complications (especially pelvic inflammatory disease) associated with gonorrhea and chlamydia infections. However, given the current knowledge that Bacterial Vaginosis is also associated with pelvic inflammatory disease and increased risk for HIV infection, the same concerns ought to apply to vaginal infections. 


\section{vi) Prevalence of syphilis infection}

The VDRL and RPR tests were used to identify clients with syphilis infection. According to the VDRL test, $7.1 \%$ of the clients tested positive for syphilis infection compared with $3.9 \%$ on the RPR test. The VDRL is a more specific measure of syphilis infection but stays positive for a long time even after successful treatment, while the RPR - a less specific test becomes negative within twelve months following treatment. Therefore, the RPR is a better measure of more recent and untreated infections than the VDRL. In order to have a more reliable estimate of the prevalence of syphilis, only those clients testing positive on both tests $(3 \%)$ were considered.

The policy implication for these data is the finding of a prevalence rate for syphilis of $3 \%$. This is high, especially considering that interventions in populations with lower

prevalence rates result in a major public health impact ${ }^{21}$. Therefore, screening and treating family planning clients for syphilis needs to be considered as a major intervention in reducing its prevalence and adverse effects on pregnancy outcome.

Intervening during the period before pregnancy occurs may have better impact on reducing adverse effects during pregnancy, given that most of these occur in the first trimester when most women have not started attending antenatal clinics.

\section{vii) Incidence of Opthalamia neonatorum}

Opthalamia neonatorum, an infection of the eyes of newborn babies, appears to be common in Zimbabwe. Of the 430 women who had given birth in the 24 months preceding the study, $18.8 \%$ reported that their babies had eye infections in the neonatal period suggestive of Opthalamia neonatorum.

The high prevalence of eye infections in the neonatal period concurs with reports from the Harare City Health Department ${ }^{22}$ of an increase in Opthalamia neonatorum cases at their health facilities. Given that most cases of this infection are caused by gonorrhea and/or chlamydia which are found in less than $5 \%$ of antenatal /FP clients, there is need to identify what other organisms may be responsible for the large number of infected cases reported. These data also support the call for strengthening strategies that screen women for other RTIs during antenatal care.

Data from several Situation Analysis Studies undertaken in the region ${ }^{23}$ (two of them in Zimbabwe) have shown that revisit clients (clients visiting the clinics for re-supplies) are rarely assessed. This is based on the assumption that requiring regular check-ups introduces medical barriers to family planning clients who are at low risk for RTIs and as such do not need clinical examinations.

However, this study found that nearly one-third of revisit and clients attending for their annual check-ups had an RTI on laboratory testing and nearly two-thirds had symptoms and/or signs suggestive of an infection. These data show that there is a need to regularly 
assess these clients for symptoms and signs related to RTIs. This should feasible given that time utilization studies in the region have shown that service providers have some lag time that could be used for proper assessment of clients. These studies have also shown that adding STI risk assessment for new family planning clients does not increase the client contact time. 


\section{PREVALENCE OF RTI AND HIV/AIDS RISK FACTORS}

All the women who agreed to participate in the study were interviewed about the presence/absence of RTI and HIV risk factors by a trained interviewer at the end of the clients' consultation with clinic staff. This information was collected in two stages. First, service providers used a checklist (Appendix i) to record the client's clinical history including symptoms of RTIs, and the findings of the clinical and pelvic examinations.

Second, all new and revisit clients who agreed to provide a specimen for laboratory testing were interviewed by a trained interviewer after the consultation and specimen collection using a standardized checklist to obtain information on the RTI and HIV/AIDS risk factors. The RTI/HIV risk assessment checklist had a total of 23 risk factor items covering clients' and partners' sexual behavior, history of RTI symptoms in clients, clients' perception of their own risk status for RTIs and HIV infection, and history of RTI symptoms in their partners.

Behavioral risk factors were relatively common among the study population. Forty-seven percent of the study clients had at least one of the behavioral risk factors and $22 \%$ had more than one. Frequent travel and staying away from home were the most frequently mentioned behavioral risk factors. Although few women reported frequent change of sex partners, it is important to note that $11.7 \%$ said that they had sex with a new partner in the last sexual intercourse encounter (Figure 3).

Figure 3: Percent of clients with behavior risk factors (\% clients $N=1634)$

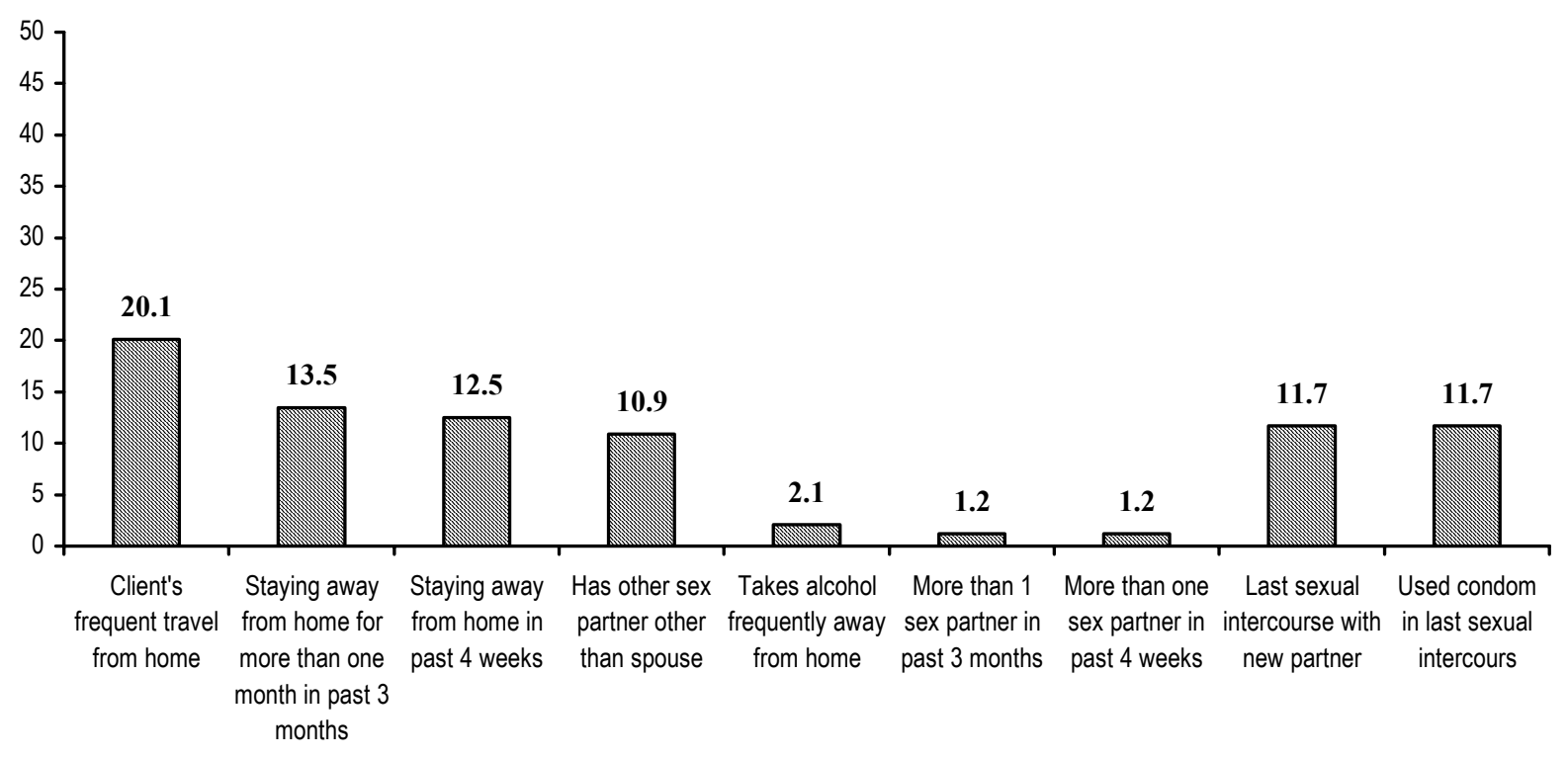


A significant proportion (35\% and 30\%) of the study clients considered themselves to be at risk for RTI and HIV/AIDS, respectively. Clients seeking RTI services were more likely to perceive themselves to be at increased risk for RTIs and HIV/AIDS $(57 \%$ and $47 \%$, respectively). In addition it is worth noting that although more than $30 \%$ of the clients perceived themselves to be at an increased risk for RTIs and HIV infection, only $12 \%$ had used a condom during the last sexual intercourse. This low use of condoms reported by the study clients may be a reflection of their poor negotiating skills and/or lack of power even when they recognize the risks they are taking.

Sixty-five percent of the study clients reported having experienced at least one RTI symptom, while $42.3 \%$ had experienced more than one symptom in the 12 months preceding the study. The most commonly reported symptom was lower abdominal pain followed by vaginal discharge (yellow discharge, blood stained discharge or foul smelling discharge), painful sexual intercourse and pain on passing urine, respectively (Figure 4).

Clients seeking RTI services were more likely to report symptoms in the partner than the overall study population. One-quarter of all study clients reported that their partners had experienced at least one RTI symptom in the four weeks preceding the study.

However, of the 410 clients seeking RTI services, 149 (36.3\%) reported that their partners had experienced at least one RTI symptom over the same period. History of lower abdominal pain was the most commonly mentioned symptom followed by pain on passing urine for both categories of clients (Table 6).

Table 6: Percent of clients reporting RTI symptoms in partner

\begin{tabular}{|c|c|c|}
\hline $\begin{array}{l}\text { History of RTI } \\
\text { symptoms in } \\
\text { partner }\end{array}$ & $\begin{array}{l}\text { Percent } \\
\text { all clients } \\
N=1634\end{array}$ & 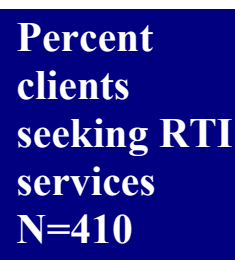 \\
\hline Lower & 15.4 & 21 \\
\hline abdominal pain & 7.8 & 9.2 \\
\hline Yellow & 14.5 & 19.9 \\
\hline discharge & 8.9 & 13.3 \\
\hline $\begin{array}{l}\text { Pain on passing } \\
\text { urine }\end{array}$ & 6.9 & 8.4 \\
\hline $\begin{array}{l}\text { Genital } \\
\text { ulcer/wound }\end{array}$ & 3.8 & 5.9 \\
\hline $\begin{array}{l}\text { Swelling in the } \\
\text { groin }\end{array}$ & & \\
\hline $\begin{array}{l}\text { Has urethral } \\
\text { discharge }\end{array}$ & & \\
\hline
\end{tabular}

Besides asking clients about RTI symptoms in their partners, the clients were asked if they had taken any medication for RTIs in the 12 months preceding the study. Only $14 \%$ 
of clients said that they had. Of those clients who attended the clinics for RTI services, $26 \%$ had taken RTI medication over the same period. Women were asked whether their partners had taken any medication for RTIs in the four weeks preceding the study. Since some women may not know what medications for RTIs look like, they were given a description of antibiotics and asked if their partners had taken any over the same period.

More than one-half of the women coming for RTI services said that their partners had either been on RTI medication or antibiotic treatment over the stated period. Considering all study clients, one-third of the study clients reported use of RTI medication among their partners. These data suggest that many men had used antibiotics in the four weeks preceding the study.

Data from this study show that risk factors are relatively common among family planning clients. However, some of the more traditional risk factors like rate of change of sex partners are not common, and therefore these risk factors may be more important in partners rather than the women themselves.

\section{Return for follow-up visits}

The current algorithms used to manage RTIs in Zimbabwe recommend treatment regimens that require clients to return to the clinics for assessment after completion of the initial dose of treatment. In this study all clients consenting to participate in the study for whom specimens for laboratory testing were collected were requested to return to the clinic at specified dates.

Findings from this study show that fewer than $20 \%$ of clients returned for follow up regardless of whether a syndromic diagnosis was made and the client started on medication. These findings suggest that regardless of diagnosis clients do not return for follow-up when requested to do so.

This low return for follow-up has important implications for policy and service provider guidelines in the management of RTIs. It has led to the recommendation that all clients with vaginal discharge be treated for cervical infections, due to the belief that cervical infections have more severe complications compared with vaginal infections. However, with the emerging knowledge that Bacterial Vaginosis (a more common infection) causes pelvic inflammatory diseases and also increases the risk for HIV infection, there is need to review the recommendations. 


\section{EFFECTIVENESS OF SYNDROMIC MANAGEMENT}

The effectiveness of different algorithms for diagnosing and managing RTIs was determined using the sensitivity 24 , specificity 25 and positive predictive value 26 for each of the algorithms. The sensitivity, specificity and positive predictive values were calculated using the number of true positives, true negatives, false positives and false negatives associated with each algorithm 27 .

Of the 1634 clients who consented to participate in the study, laboratory test results were available for all the five RTIs for 1623 clients. Therefore it is only these clients who are considered in the effectiveness and cost-effectiveness analysis.

\section{Effectiveness of current national algorithms in Zimbabwe}

The national algorithms in Zimbabwe recommend that if a client presents with a symptom of vaginal discharge, she should be examined and if the examination reveals that she has a vaginal discharge then she should be treated for vaginal discharge syndrome 28 .

The national algorithms also recommend that when pelvic examination is not possible at a facility, all clients with vaginal discharge symptom should be treated for cervical and vaginal infections. In this study, 535 (33\%) of study clients had clinical evidence of vaginal discharge yet only $284(53 \%)$ were diagnosed to have vaginal discharge syndrome and treated according to the national algorithms (Figure 5). The data also show that $298(18.3 \%)$ of the study clients had both symptoms and signs of vaginal discharge. However, a diagnosis of vaginal discharge syndrome was made in $194(65 \%)$ only. It is not clear why a diagnosis was not made in the rest of the clients who had vaginal discharge as is recommended by the national algorithms. 
Figure 5: Proportion of clients with vaginal discharge or lower abdominal pain symptom and $\backslash$ or sign for whom staff made a syndromic dianosis

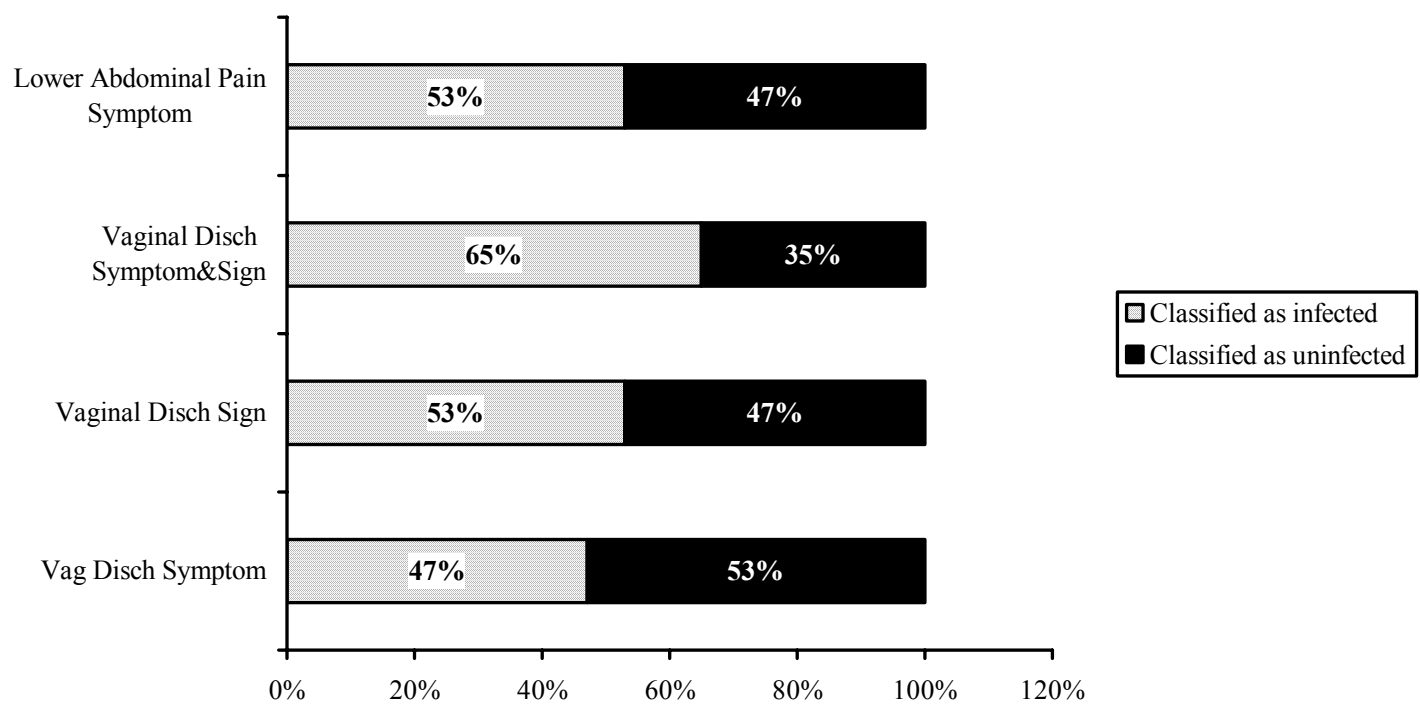

The same algorithms recommend that clients complaining of lower abdominal pain should be treated for pelvic inflammatory disease (PID) syndrome. In this study 698 (43\%) of the clients complained of lower abdominal pain but only $53 \%$ of those who complained were diagnosed and treated for PID according the national algorithms. These findings suggest that clinical findings do not always guide the clinicians' decision to diagnose and treat RTIs. The data also suggest that clinicians do not always follow the national algorithms even when specific efforts are put in training them and ensuring that the algorithms, supplies, equipment and drugs are available.

Another measure of effectiveness used was the proportion of women classified by providers as having an RTI using syndromic approach who had a positive laboratory test for RTIs.A total of 635 (39\%) women were classified as having an RTI using the syndromic approach. Of the women so classified, 298 (47\%) did not have any laboratory evidence of an RTI. The data also show that 187 (36\%) of women with laboratory evidence of an RTI were not classified as having any of the RTI syndromes by the services providers. Considering only those women who had a negative laboratory test for an RTI, 298 (27\%) were classified as having an infection using the syndromic approach. Data on Figure 6 shows that women classified by providers as having both the vaginal and lower abdominal RTI syndromes were more likely to have a positive laboratory test for an infection. Classification into the lower abdominal pain RTI syndrome was associated with the lowest probability of having a positive laboratory test for an RTI. In summary, these findings show that using the different RTI syndromes to classify women 
into infected and non-infected is associated with significant proportions of false positives and false negatives.

Figure 6: Proportion of clients for whom staff made a syndromic diagnosis who had a positive lab test for an RTI

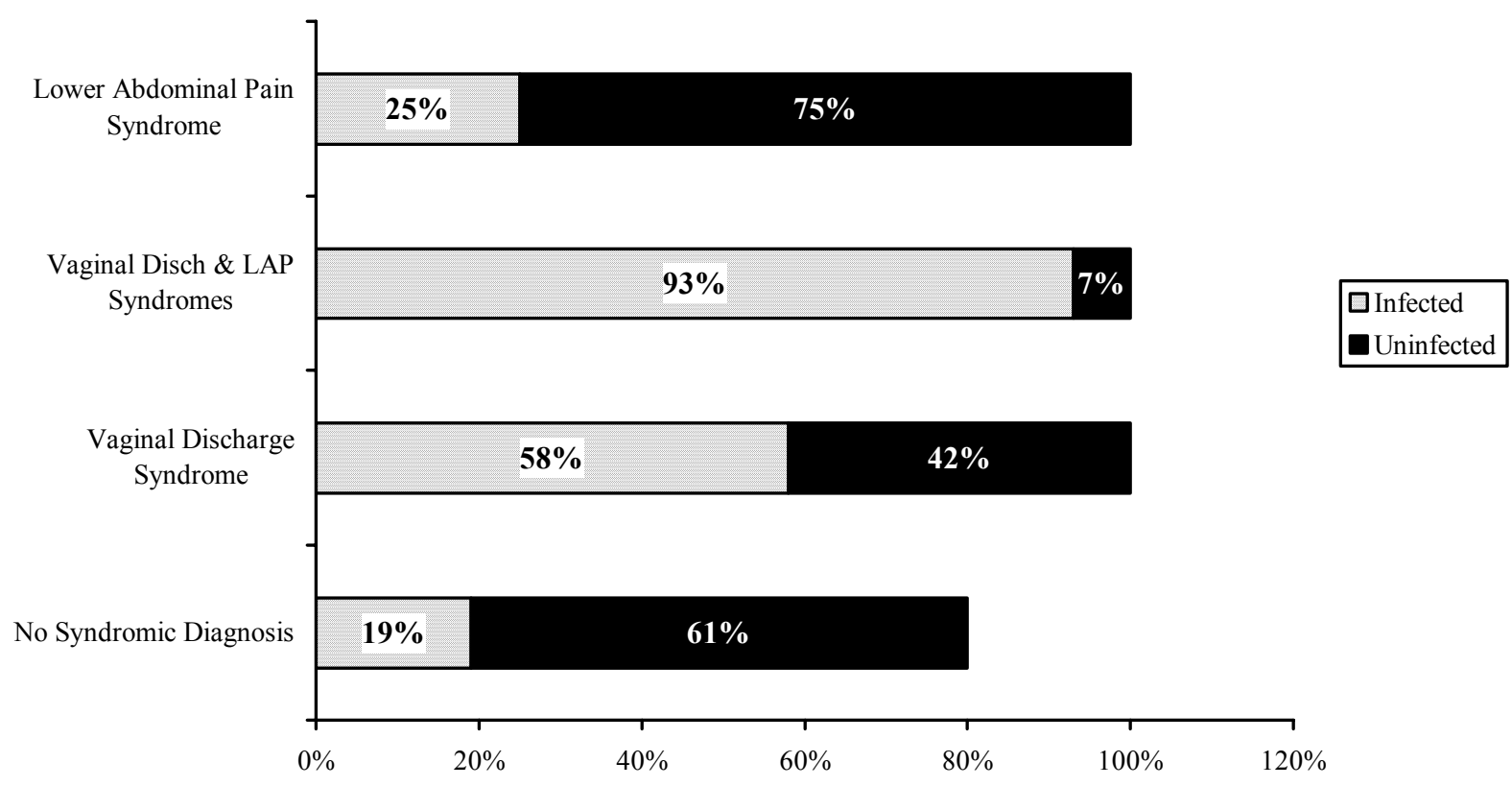

\section{Effectiveness of Symptoms and/or signs in predicting RTIs}

The concept of syndromic management is based on the assumption that symptoms and/or signs can be used to predict the presence of certain infections. For example, vaginal discharge symptom and/or sign is believed to predict the presence of gonorrhea, chlamydia, trichomoniasis, candida and bacterial vaginosis. These infections are grouped into cervical infections (gonorrhea, chlamydia) and vaginal infections (trichomoniasis, candida and bacterial vaginosis). The implications of the two groups of infections differ markedly warranting different approaches to treatment. The effectiveness of the vaginal discharge symptom and/or sign in predicting the presence of these groups of infections is important as it has a major bearing on the overall application of syndromic algorithms by the providers.

Therefore, further analysis was undertaken to determine the effectiveness of using these symptoms to predict the presence of RTIs, assuming that the providers would follow the national algorithms and classify all clients reporting these symptoms and/or found to have the signs on examination as having an RTI. In this analysis, the effectiveness of these symptoms/signs to predict the presence of RTIs among only those clients whose reasons 
for visiting the clinics included receiving STI services was compared with when the symptoms and/or signs are used to screen all clients attending the clinics for RTIs.

Table 7: Sensitivity of vaginal discharge andlor lower abdominal pain symptoms or signs in predicting RTIs

\begin{tabular}{|l|l|l|l|}
\hline \multirow{2}{*}{$\begin{array}{l}\text { Clinical } \\
\text { information }\end{array}$} & Type of RTI & Sensitivity \\
\cline { 3 - 4 } & & All Clients (\%) & $\begin{array}{l}\text { RTI clients only } \\
(\%)\end{array}$ \\
\hline \multirow{2}{*}{$\begin{array}{l}\text { Vaginal discharge } \\
\text { symptom }\end{array}$} & Cervicitis & 46 & 72 \\
\cline { 2 - 4 } & Vaginitis & 35 & 69 \\
\hline \multirow{2}{*}{$\begin{array}{l}\text { Vaginal discharge } \\
\text { sign }\end{array}$} & Cervicitis & 47 & 62 \\
\cline { 2 - 4 } & Vaginitis & 39 & 60 \\
\hline \multirow{2}{*}{$\begin{array}{l}\text { Vaginal discharge } \\
\text { symptom and sign }\end{array}$} & Cervicitis & 33 & 55 \\
\cline { 2 - 4 } & Vaginitis & 24 & 40 \\
\hline \multirow{2}{*}{$\begin{array}{l}\text { Lower abdominal } \\
\text { pain }\end{array}$} & Cervicitis & 63 & 86 \\
\cline { 2 - 4 } & Vaginitis & 41 & 68 \\
\hline
\end{tabular}

Data on Table 7 show the sensitivity for vaginal discharge symptom and/or sign and lower abdominal pain symptom. The sensitivity for these symptoms and signs when used to screen all women attending family planning clinics for cervical or vaginal infections is low and would therefore result in a higher proportion of false negatives.

However, when used to screen for these infections among clients seeking RTI services within the family planning clinic, the sensitivity is much higher; therefore, there is a smaller proportion of false negatives. The data also show that the lower abdominal pain symptom has a better sensitivity compared with the vaginal discharge symptom and/or sign when used to predict the presence of either cervical or vaginal infections in both categories of clients.

Data from this study show that the vaginal discharge and lower/abdominal pain symptoms and/or signs have poor specificity when used to identify women with RTIs among those clients seeking RTI services from family planning clinics compared to when they are used to screen all clients attending the clinic for RTIs. Therefore, the proportion of false positives will be higher among clients seeking RTI services compared with all clients attending a family planning clinic when the symptoms and signs are used to screen for cervical and vaginal infections. These data also show that these symptoms and signs have a higher specificity when used to identify clients with cervical infections, compared with vaginal infections among all clients attending the clinics (Table 8). 
Table 8: Sensitivity of vaginal discharge and $\backslash$ or lower abdominal pain symptoms or signs in predicting RTIs

\begin{tabular}{|l|l|l|l|}
\hline Clinical information & Type of RTI & \multicolumn{2}{|l|}{ Specificity } \\
\cline { 3 - 4 } & & All Clients (\%) & $\begin{array}{l}\text { RTI clients only } \\
(\%)\end{array}$ \\
\hline \multirow{2}{*}{ Vaginal discharge symptom } & Cervicitis & 96 & 41 \\
\cline { 2 - 4 } & Vaginitis & 70 & 44 \\
\hline \multirow{2}{*}{ Vaginal discharge sign } & Cervicitis & 97 & 55 \\
\cline { 2 - 4 } & Vaginitis & 70 & 60 \\
\hline \multirow{2}{*}{$\begin{array}{l}\text { Vaginal discharge symptom } \\
\text { and sign }\end{array}$} & Cervicitis & 96 & 66 \\
\cline { 2 - 4 } & Vaginitis & 84 & 70 \\
\hline \multirow{2}{*}{ Lower abdominal pain } & Cervicitis & 58 & 26 \\
\cline { 2 - 4 } & Vaginitis & 57 & 22 \\
\hline
\end{tabular}

Data on Table 9 show that the vaginal discharge and lower abdominal pain symptoms and/or signs have a better PPV when used to identify clients with vaginal infections compared to when they are used to identify clients with cervical infections. However, in both situations the PPV is below $50 \%$. Therefore, using these symptoms or signs leads to identification of a small proportion of the true positives. The data also show that there are no significant differences in the PPV for both categories of clients.

Table 9: Positive predictive values of vaginal discharge andlor lower abdominal pains symptoms or signs in predicting RTIs

\begin{tabular}{|l|l|l|l|}
\hline \multicolumn{2}{|c|}{ Clinical information } & $\begin{array}{l}\text { Specificity } \\
\text { All Clients } \\
(\%)\end{array}$ & $\begin{array}{l}\text { RTI clients only } \\
(\%)\end{array}$ \\
\hline \multirow{3}{*}{$\begin{array}{l}\text { Vaginal discharge } \\
\text { symptom }\end{array}$} & Cervicitis & 6 & 9 \\
\cline { 2 - 4 } & Vaginitis & 32 & 34 \\
\hline Vaginal discharge sign & Cervicitis & 6 & 10 \\
\cline { 2 - 4 } & Vaginitis & 34 & 38 \\
\hline \multirow{2}{*}{$\begin{array}{l}\text { Vaginal discharge } \\
\text { symptom and sign }\end{array}$} & Cervicitis & 8 & 11 \\
\cline { 2 - 4 } & Vaginitis & 38 & 41 \\
\hline \multirow{2}{*}{ Lower abdominal pain } & Cervicitis & 6 & 8 \\
\cline { 2 - 4 } & Vaginitis & 28 & 27 \\
\hline
\end{tabular}


In summary, data from this study have shown that the current national algorithms used to syndromically manage clients for RTIs in Zimbabwe are ineffective when used in a family planning clinic. Use of the symptom-only-based algorithms is associated with a high number of false positives and false negatives.

The study identified two major reasons why the current algorithms may not be effective. First, the clinicians do not utilize the information obtained during consultations to diagnose and manage clients with symptoms and/or signs suggestive of an RTI. Secondly, the vaginal discharge and lower abdominal symptoms and signs have poor positive predictive values for both cervical and vaginal infections. 


\section{EVALUATING THE COST AND EFFECTIVENESS OF ALTERNATIVE WAYS OF ADDING RTI SERVICES TO ZNFPC CLINICS}

The previous sections of this report have focused on the ability of clinicians to follow syndromic management guidelines and the ability of those guidelines, when applied, to correctly identify a client with an RTI. This section of the report will evaluate four possible algorithms that could be used to provide RTI services in ZNFPC clinics. For each possible algorithm, we estimate the cost to ZNFPC and the number of women infected with RTIs who would have been correctly treated had the algorithm been followed as designed. The final section will discuss the implications of selecting a particular algorithm within the context of available resources in Zimbabwe.

\section{Alternative Algorithms for Providing RTI Services}

There are four possible algorithms that could be used to provide RTI services to women attending family planning clinics. One algorithm is to respond only to those clients who seek RTI services using the syndromic approach $(n=410$ in our sample of clients). The second option is to use the syndromic approach to screen for RTIs among all clients attending the family planning clinic $(\mathrm{n}=1,623)$. A third option would be to first screen all family planning clients using the syndromic approach, followed by laboratory testing for those clients identified to have any of the RTI syndromes. The fourth algorithm is one where all women attending the family planning clinic would undergo laboratory testing for the common RTIs.

These alternative algorithms are listed in terms of increasing aggressiveness in identifying women with RTI infections. In addition, the laboratory-based approaches represent alternatives that should be more accurate than reliance upon the syndromic management guidelines alone. However, this increased precision is likely to come at an increased cost to the program.

\section{Effectiveness of Alternative Algorithms for Providing RTI Services}

The measure of effectiveness used in this analysis is the number of women with RTIs who are correctly treated. With this measure of effectiveness, there is no penalty for incorrectly diagnosing a woman as having a RTI. However, if an algorithm tends to incorrectly identify women as infected, the drug costs will be higher than necessary, so the cost part of the cost-effectiveness ratio will be inflated.

Data in Table 10 show the number of women who would be diagnosed as infected under the four alternative management algorithms. This number is further divided into two groups: a) the number of women with RTIs who are correctly treated, and b) the number of women who are given drugs unnecessarily. The first subgroup corresponds to the measure of effectiveness used in the cost-effectiveness analysis. The second subgroup corresponds to those women for whom drug costs are incurred with no gain in effectiveness. 
Table 10 highlights the limitations of the syndromic approach to diagnosis - poor accuracy. When the syndromic approach is used for diagnosis, many women are given drugs unnecessarily (56.4\% of women treated when applied to the subset of clients seeking RTI services, $46.9 \%$ of women treated when applied to all FP clients). In addition, the syndromic approach fails to identify many of the women with RTIs. When applied to the subset of women seeking services, only $27.1 \%$ of the women with RTIs came to the clinic seeking services, so many of the women with RTIs remain untreated. When the syndromic approach is used to screen all FP clients, 35.7\% of the women with RTIs do not meet the syndromic criteria for suspected infection.

Table 10: Accuracy of Four RTI diagnostic Algorithms for FP clients $(n=1,623)$

\begin{tabular}{|l|c|c|c|}
\hline Diagnostic Algorithm & $\begin{array}{c}\text { \# of Women } \\
\text { Classified as } \\
\text { Infected }\end{array}$ & $\begin{array}{c}\text { \# of Women } \\
\text { Correctly } \\
\text { Treated }\end{array}$ & $\begin{array}{c}\text { \# of Women } \\
\text { Given Drugs } \\
\text { Unnecessarily }\end{array}$ \\
\hline $\begin{array}{l}\text { Syndromic approach for clients seeking } \\
\text { RTI services (n=410/1,623) }\end{array}$ & 298 & 130 \\
\hline $\begin{array}{l}\text { Syndromic screening for all FP clients } \\
\text { Syndromic screening for all FP clients, } \\
\text { followed by laboratory testing of all clients } \\
\text { with suspected RTI }\end{array}$ & 635 & 337 & 298 \\
\hline
\end{tabular}

Table 10 also demonstrates the potential role of laboratory tests in the diagnostic and treatment process. If laboratory tests are used as a complement to syndromic management the unnecessary use of drugs can be avoided. However, only when laboratory tests are used as a substitute for syndromic management will both the unnecessary use of drugs and missed cases be avoided.

This increased accuracy will come at the cost of the laboratory tests used for diagnosis. The next section will explore the relative cost of these alternative algorithms.

\section{Cost of Alternative Algorithms for Providing RTI Services}

The cost analysis undertaken in this study focused on the costs to ZNFPC associated with implementing the alternative algorithms. These costs are comprised of the costs of laboratory tests (if used) to detect RTIs and the drugs (broad spectrum or targeted) and related supplies used to treat RTIs. Labor costs were not included since a previous study 30 showed that staff had sufficient unallocated time to provide syndromic diagnosis to those clients who would be eligible for this service. 
A previous analysis indicated that training costs were very low when annualized and allocated to visits, and therefore were not considered in this analysis. Finally the costs associated with any later treatment of missed infections were not considered.

\section{Costs of laboratory tests and related supplies}

For this study, all laboratory tests used to either confirm a syndromic diagnosis or as a screening mechanism were purchased by ZNFPC from a local lab. The Zimbabwe public laboratories supplied the charges for RTI tests to the family planning clinic. To test for all five potential RTIs, the total cost per sample was US\$24.58.

When a laboratory test is used, there are additional costs associated with collection of the specimen. This is estimated to be US\$ 0.60 for a total cost per laboratory test of US\$ 25.18 .

\section{Costs of Drugs for RTI Treatment}

The estimated costs of drugs used for RTI treatment were calculated by multiplying the quantities of specific drugs recommended by the RTI treatment protocols 31 by the acquisition cost to ZNFPC for the drugs. Due to frequent shortages of drugs at the Government Medical Stores (GMS), ZNFPC often makes drug purchases in the local market. Therefore the local market prices as obtained from Geddes Medical Suppliers were used in these calculations.

According to the Flowcharts for the Management of STDs developed for the Zimbabwe National AIDS Coordination Program, a woman presenting with or found to have vaginal discharge and/or lower abdominal pain syndromes would be treated with a broad range of drugs simultaneously 32 . The specific drugs and dosages prescribed would depend upon which syndromes are believed to be present by the clinician. On average, the broad range approach costs about US\$ 13.50 per case treated.

When laboratory tests are employed prior to treatment, the laboratory test results will be used to guide prescribing for the specific infectious organism(s) found to be present in the woman. Because drugs can be targeted to the specific infectious organism(s), the drug costs will be lower per woman treated when laboratory test results are used to confirm or make the diagnosis.

Data in Table 11 summarize the expected program costs under alternative algorithms if the national guidelines for management of clients were to be followed for the sample of clients in our study.

If the syndromic approach were applied to the subset of clients seeking RTI services $(\mathrm{n}=$ 410) 298 women would be prescribed drugs for treatment of suspected RTIs. This results in a cost to ZNFPC of US\$ 4,024. 
Expanding the syndromic approach to all FP clients would result in treating 635 women for a suspected RTI. The total cost to ZNFPC would then increase to US\$ 8,605. However, as shown in Table 10, this increased cost is accompanied by increased effectiveness (the number of women with RTIs who are correctly treated).

\section{Table 11: Cost of ZNFPC of Four RTI diagnostic Algorithms for FP Clients} $(n=1,623$

\begin{tabular}{|l|c|c|c|c|c|}
\hline Diagnostic Algorithm & $\begin{array}{c}\text { \# of Women } \\
\text { classified } \\
\text { as Infected }\end{array}$ & $\begin{array}{c}\text { \# of Women } \\
\text { with Positive } \\
\text { Lab Test }\end{array}$ & $\begin{array}{c}\text { Total } \\
\text { Cost of } \\
\text { Drugs } \\
\text { (US\$) }\end{array}$ & $\begin{array}{c}\text { Total } \\
\text { Cost of } \\
\text { Lab } \\
\text { Tests(US }\end{array}$ & $\begin{array}{c}\text { Total Cost } \\
\text { (Drugs + } \\
\text { Lab) (US\$) }\end{array}$ \\
\hline $\begin{array}{l}\text { Syndromic approach for clients } \\
\text { seeking RTI services } \\
\text { (n=410/1,623) }\end{array}$ & 298 & N/A & 4,024 & N/A & 4,024 \\
\hline $\begin{array}{l}\text { Syndromic screening for all FP } \\
\text { clients }\end{array}$ & 635 & N/A & 8,605 & N/A & 8,605 \\
\hline $\begin{array}{l}\text { Syndromic approach for all FP } \\
\text { clients, followed by laboratory } \\
\text { testing of all clients with } \\
\text { suspected RTls }\end{array}$ & 635 & 337 & 733 & 15,989 & 16,722 \\
\hline $\begin{array}{l}\text { Laboratory testing for all FP } \\
\text { clients }\end{array}$ & N/A & 524 & 951 & 40,867 & 41,819 \\
\hline
\end{tabular}

The algorithm that uses laboratory tests as a complement to the syndromic approach, saves a substantial amount on drugs because only 337 women are prescribed treatment and the treatment can now be targeted to the specific infectious organism(s) found to be present. However the savings from reduced use of prescription drugs is more than offset by the increased costs associated with performing laboratory tests for the 635 women initially diagnosed as infected.

Finally, when laboratory tests are used to screen all FP clients, only those clients with positive lab test results would be prescribed drugs and the drugs prescribed would target the specific infectious organisms. Therefore, compared to the syndromic approach, there is a saving in drugs. However, because each woman would receive a laboratory test, the laboratory costs offset the savings on drugs resulting in a total cost to ZNFPC of US\$ 41,819 . Only in this case, however, would all women with RTIs receive treatment, so it is the most costly and the most effective alternative.

\section{Evaluating the Cost-Effectiveness and Feasibility of Alternative Algorithms for Providing RTI Services}

This section of the report will assess the cost-effectiveness and the feasibility of the alternative algorithms for providing RTI services within ZNFPC clinics.

Cost-effectiveness is reported as a ratio of cost to effectiveness. If trying to assess the productivity or efficiency of an alternative, the average cost effectiveness ratio is most 
useful. The average cost-effectiveness ratio estimates the cost per unit of effectiveness for each alternative. In our study, this would be the cost per correctly treated woman with an RTI. However, this ratio is misleading when trying to compare alternative programs since it implicitly assumes that there is an alternative that has both zero cost and zero effectiveness.

When trying to compare alternatives so that one can be selected or so that funding priorities can be established, the incremental cost-effectiveness ratio ${ }^{33}$ should be used. The incremental cost-effectiveness ratio estimates the cost per additional unit of effectiveness when moving from one alternative to a more effective alternative. This ratio indicates the additional investment required to obtain one more unit of effectiveness. In our study this would be the additional cost required to treat one more woman with a RTI correctly.

Finally, the feasibility of these alternatives for ZNFPC is assessed based upon the estimated cost per client. This represents the magnitude of resources that ZNFPC would be required to commit per client to pursue the alternative algorithms. These values will be compared to the estimated total per capita spending on health care in Zimbabwe in 1998.

\section{Average Cost-Effectiveness of Alternative Algorithms}

Table 12 presents the average cost-effectiveness ratio of the four alternative algorithms. In this case, the syndromic screening of all FP clients is the most efficient alternative US\$ 25.53 per woman with a RTI correctly treated. The next most efficient algorithm would be to use the syndromic approach for those women seeking RTI services (US\$ 30.92). The algorithms that use laboratory test results are not nearly as efficient due to the relatively high costs of laboratory tests. This suggests that unless ZNFPC can find a way to lower the cost of laboratory testing, that these algorithms are not a very efficient use of resources.

\section{Incremental Cost-Effectiveness of Alternative Algorithms}

Also shown in Table 12 is the incremental cost of moving from the least costly alternative (using the syndromic approach for those women seeking RTI services) to each of the other more costly alternative algorithms. Even though the syndromic screening of all FP clients is the most efficient alternative, it would require an investment of an additional US\$22.15 to treat one more woman with a RTI correctly. This cost is almost two-thirds higher than the drug cost per woman treated (US\$ 13.50) due to the large number of women who are unnecessarily given drugs (see Table 10).

The next most costly alternative, syndromic screening of all FP clients followed by laboratory testing of all clients with suspected RTI, has an incremental cost effectiveness ratio of US\$ 61.34. However, because there is no gain in effectiveness compared to syndromic screening of all FP clients (see Table 10) while there is an increase in cost, this alternative should not be considered by ZNFPC. 
Finally, the most costly alternative, screening of all FP clients with laboratory tests, would require ZNFPC to spend an additional US\$ 95.96 for each additional woman with a RTI correctly treated. This is almost four times the cost of the laboratory test used to screen clients because only $34.4 \%$ of the ZNFPC clients in our sample are infected yet $100 \%$ would receive a laboratory test as part of the screening.

Table 12: Cost-Effectiveness and Feasibility of Four RTI Diagnistic Algorithms for FP clients $(n=1,623)$

\begin{tabular}{|l|c|c|c|}
\hline Diagnostic Algorithm & $\begin{array}{c}\text { Average } \\
\text { Cost- } \\
\text { Effectiven ess } \\
\text { Ratio }\end{array}$ & $\begin{array}{c}\text { Incremental } \\
\text { Cost- } \\
\text { Effectiven ess } \\
\text { Ratio }\end{array}$ & $\begin{array}{c}\text { Cost per } \\
\text { Client } \\
\text { (US } \$)\end{array}$ \\
\hline $\begin{array}{l}\text { Syndromic approach for clients seeking } \\
\text { RTI services ( }=410 / 1,623)\end{array}$ & $\$ 30.92$ & $\begin{array}{c}\text { Reference } \\
\text { Algorithm }\end{array}$ & $\$ 2.48$ \\
\hline Syndromic screening for all FP clients & $\$ 25.53$ & $\$ 22.15$ & $\$ 5.30$ \\
\hline $\begin{array}{l}\text { Syndromic screening for all FP clients, } \\
\text { followed by laboratory testing of all } \\
\text { clients with suspected RT Is }\end{array}$ & $\$ 49.62$ & $\$ 61.34$ & $\$ 10.30$ \\
\hline Laboratory testing of all FP clients & $\$ 79.81$ & $\$ 95.96$ & $\$ 25.77$ \\
\hline
\end{tabular}

\section{Feasibility of Alternative Algorithms}

Finally, in order to assess the feasibility of the alternative algorithms the cost per client is computed. To do this we divide the total cost associated with each algorithm in Table 13 by the 1,623 women in our sample. These figures are shown in the last column of Table 14. These estimated costs per client could then be compared to the estimated total per capita spending on health care in Zimbabwe. In 1998, we estimate this to be US\$ $47.12^{34}$. This total includes both public and private sector spending and represents the estimated total health care resources available per person in Zimbabwe.

With this in mind, the use of the syndromic approach for women seeking RTI services would correspond to US\$ 2.48 per client or $5.3 \%$ of the resources available per woman.

Increasing expenditures to use the syndromic approach to screen all FP clients would require US\$ 5.30 per client or $11.2 \%$ of the resources available per woman. At this point, the relative importance of RTI screening compared to other health care needs in Zimbabwe should be assessed. Is it worth over $10 \%$ of the available resources to conduct RTI screening among FP clients? 
Introducing the use of laboratory tests to improve the accuracy of the syndromic approach to screening or as a substitute for the syndromic approach would cost US\$ 10.30 or US $\$ 25.77$ respectively. This corresponds to $21.9 \%$ or $54.5 \%$ of available per capita resources.

These cost-effectiveness analyses show that the lowest cost intervention is to use syndromic management to evaluate only those FP clients seeking RTI services. However, this intervention has its drawbacks: $75 \%$ of the women with RTIs would remain undetected, and $56 \%$ of the women treated are misdiagnosed as infected and thus receive unnecessary treatment. Alternative interventions, which use laboratory tests to improve accuracy, are costly to apply on a large scale, especially in low resource settings.

Therefore, until a more cost-effective alternative to screening for RTIs can be identified, ZNFPC may want to re-assess the desirability of promoting RTI screening as an additional service offered to FP clients. 


\section{CLIENT AND SERVICE PROVIDER PERCEPTIONS ON THE INTEGRATION OF SEXUALLY TRANSMITTED INFECTION SERVICES INTO FAMILY PLANNING SERVICES}

A questionnaire was administered to all fourteen (14) service providers who participated in the study to assess how they felt about using the checklist and participation in the study. Another questionnaire was administered to 154 clients who participated in the study at the three ZNFPC clinics (i.e. Spilhaus (67\%), Lister-Bulawayo (11\%) and Mpilo $(22 \%))$.

\section{Perceptions of the service providers}

When asked about how they felt about the checklist when it was first introduced, $43 \%$ of providers thought it was rather too long, 29\% thought it was fine and the rest thought it was either cumbersome (7\%), complicated $(7 \%)$, or were not sure of its usefulness $(7 \%)$. After using the checklist for several months, their feelings had changed, with the majority $(86 \%)$ saying that it was easy to use and had greatly improved their quality of work.

The two specific difficulties mentioned by the two providers who still had some concerns with the checklist were the time it took to go through the checklist and the inclusion of some "irrelevant" questions. The majority of the providers, $(71 \%)$ said that they would like to continue using the checklist routinely.

All the service providers were completely comfortable in performing pelvic examinations for their clients. The vast majority $(93 \%)$ said that these examinations were useful (Figure $6)$.

Figure 7: Percentage of service providers who were comfortable in performing procedures and those who found them useful

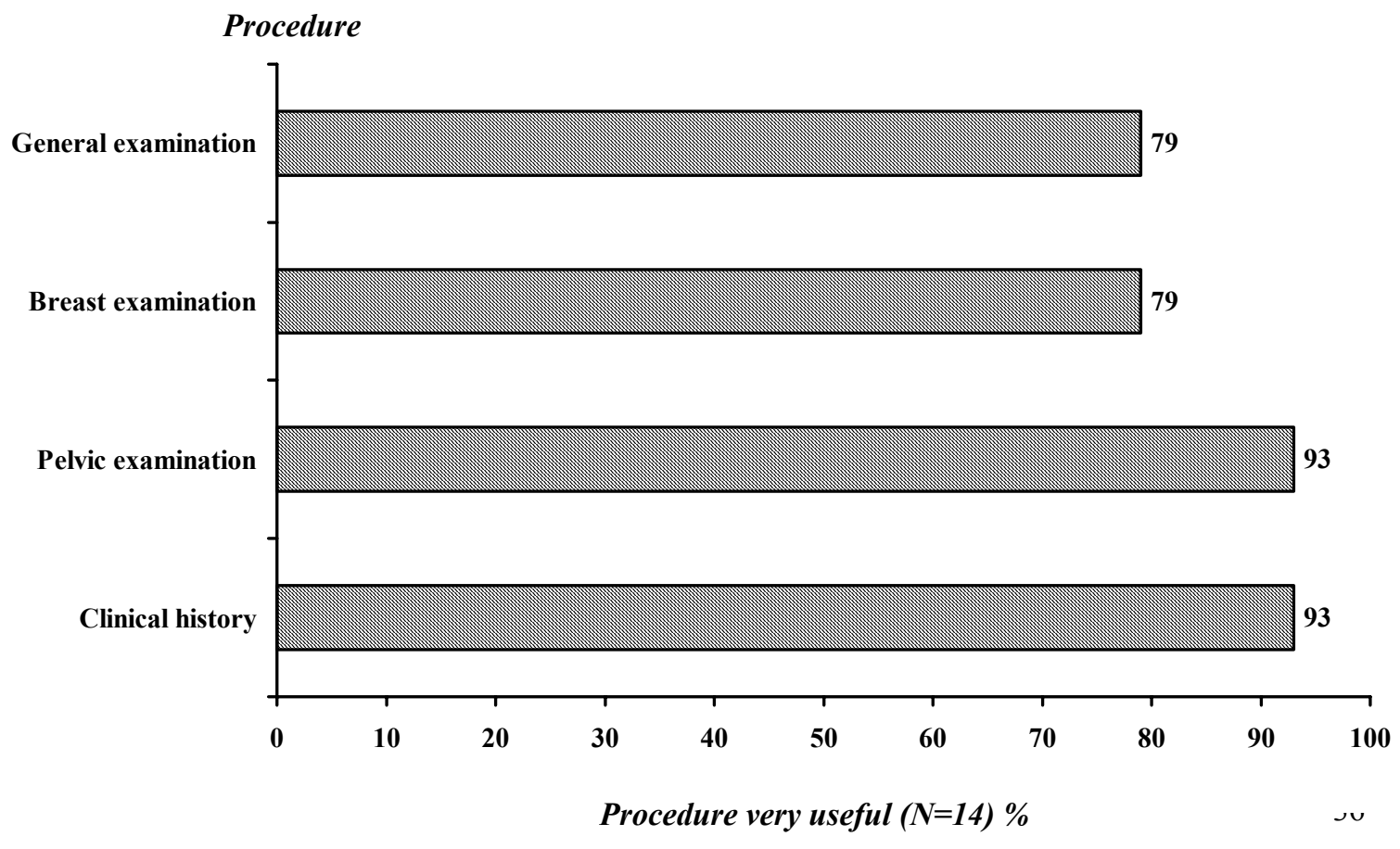


Although the majority (86\%) of the providers said that the STI/HIV risk assessment questions were useful, fewer than half indicated that they were comfortable asking clients about their sexual behavior and that of their partners.

In general, the majority felt that research studies are very useful, as they highlight aspects of service provision which require improvement. They also educate service providers on new approaches to managing clients. Specifically, the service providers reported that their participation in this study had influenced the way they do their work and how they relate to clients. They reported that their participation in the RTI project had improved their skills on counseling of STIs/HIV and the way they interact with their clients.

\section{Perceptions of the clients}

The vast majority (98\%) of the clients said that they felt comfortable responding to questions about their sexual and drinking habits and those of their partners. Asked whether they were comfortable with the speculum and pelvic examinations carried out as part of the study, 85 percent of the clients reported that they were completely comfortable while 15 percent said they were only partly comfortable and none was completely uncomfortable.

The majority of the clients (97\%) felt it was a good idea for ZNFPC to integrate RTI services into FP service delivery. The reasons given included that "integration allows STIs to be diagnosed and treated at an early stage, allows clients to get services at one clinic, provides privacy and that integration might help to reduce the level of STIs among women".

Data from this study show that using an integrated checklist in a family planning clinic is feasible and would be accepted by the service providers. The data also show that integration of RTI and family planning services is acceptable to both the service providers and clients attending family planning clinics. Contrary to perceptions that clients dislike pelvic examinations and discussion of sexual behavior, these data show that these procedures are acceptable to the majority of clients attending family planning clinics and the service providers find them useful in the management of their clients. 


\section{CONCLUDING OBSERVATIONS AND RECOMMENDATONS}

This study showed that a significant proportion of clients attending family planning clinics have RTIs and that the majority of these infections are not sexually transmitted. A large proportion of the clients with RTIs are asymptomatic, while many women reporting the presence of symptoms do not have any infection based on laboratory testing.

The study also showed that using algorithms that rely on clinic-based information is associated with a large number of false positives and false negatives leading to many management and social difficulties. Using syndromic approach to respond to only those clients seeking RTI services was found to be more effective than using it to screen all clients attending family planning clinics for RTIs. However, it was still associated with a large proportion of false negatives.

While laboratory tests could be used to improve the accuracy of syndromic diagnosis (reduce the number of false positives), the resources required to pursue such a strategy would correspond to over $20 \%$ of the per capita spending on health care in Zimbabwe.

\section{Summary of Recommendations}

i) In the absence of cost-effective approaches to the diagnosis and management of RTIs in family planning clinics, we recommend that family planning programs in the region should put more emphasis on the following activities:

Behavior change communication to reduce unsafe, unprotected sex Aggressive condom promotion both in clinic and non-clinical settings Counseling services to increase knowledge, perception of personal risk, behavior change and contraceptive method selection.

ii) Most health agencies in developing countries lack the resources required to implement syndromic management of RTIs on a large scale. For example, in Zimbabwe estimated per capita spending on all health care was US\$47 in 1998. Applying syndromic management of RTIs to all FP clients would cost more than 10 percent of these scarce resources. Given this scenario, most programs are likely to continue to use the syndromic approach to manage RTIs until a more cost-effective approach is identified. Therefore, we recommend that efforts aimed at improving its effectiveness should be continued. These efforts should include:

Improvement of skills, attitudes and perceptions of providers to enable them to undertake systematic RTI/HIV I.E.C., risk assessment and counseling for clients in order to improve on clients' knowledge of STI/HIV related symptoms and signs.

Development and use of integrated checklists should be encouraged and supported by governments and donors in the region. 
Reviews of the current RTI treatment guidelines to emphasize non-sexually transmitted infections. Many programs in the region still use algorithms that emphasize the treatment of cervical infections at the cost of neglecting the nonsexually transmitted infections.

iii) The ineffectiveness of syndromic approach in identifying women with RTIs calls for a more concerted effort in advocating for and supporting the development of simpler and more cost-effective laboratory tests.

The findings from this study support some of the guidelines put forth in a recent document from USAID, Integration of Family Planning/MCH with HIV/STD Prevention, Programmatic Technical Guidance: Priority for Primary Prevention with a Focus on High Transmitters (December 1998). The document summarizes a number of weaknesses of integrated programs, including an overemphasis on the clinical management of STDs, the ineffectiveness of the syndromic algorithm for vaginal discharge, and inadequate support for primary prevention of sexual transmission of HIV and other STDs, especially for condom promotion and behavior change intervention.

In agreement with the USAID guidance document, we recommend that as the search for more cost-effective strategies for diagnosing and managing RTIs among family planning clients continues, family planning programs in the region should put more emphasis on the following activities:

Behavior change communication to reduce unsafe, unprotected sex

Aggressive condom promotion both in clinics and non-clinical settings

Counseling services to increase knowledge, perception of personal risk, behavior change and contraceptive method selection.

This study also found that clients attending family planning clinics are comfortable discussing matters relating to their sexual behavior and that of their partners. The study also showed that it is feasible to use an integrated checklist to collect STI/HIV risk factor information and provide STI/HIV information and counseling in a standardized manner to many clients attending family planning clinics. Therefore, it should be possible to implement the recommended activities within the family planning clinic setting.

Secondly, we recommend that efforts aimed at improving the effectiveness of the syndromic approach be continued, given that most programs will continue to use the syndromic approach to manage RTIs until a more cost-effective approach is identified. For example, the large discrepancy between reported symptoms and signs found during clinical examination might be a reflection of clients' poor knowledge of the symptoms associated with these infections. The study also showed that combining information on STI/HIV risk assessment, history of RTI symptoms and clinical examination improves on the performance of the clinic-based algorithms. However, the study also found that more than $50 \%$ of service providers were not comfortable discussing sexual behavior issues with their clients. Therefore there is a need to improve skills of providers and to encourage them to undertake systematic STI/HIV I.E.C. for clients in order to improve clients' knowledge of STI/HIV related symptoms and signs. 
Thirdly, the magnitude of resources required to perform syndromic management on a large scale is high, especially in low-resource settings. For example, in Zimbabwe, estimated per capita spending on all health care in 1998 was US\$47. The least costly screening strategy would require devoting more than $10 \%$ of these scarce resources to RTI screening. Therefore, we recommend that should programs choose to continue using the syndromic approach, the strategy that responds to only those clients requesting RTI services should be adopted.

In addition, data from the study showed that the checklist enabled more clients with symptoms and signs suggestive of RTIs to be identified and the vast majority of clients received STI/HIV counseling. Therefore, development and use of integrated checklists should be encouraged and supported by governments and donors in the region.

Also many programs in the region use algorithms that emphasize the treatment of cervical infections at the cost of neglecting the non-sexually transmitted infections. However, data from this study show that the non-sexually transmitted infections are much more common. Given recent evidence indicating that bacterial vaginosis may be associated with increased transmission of HIV infection and pelvic inflammatory disease, there is need to review the treatment guidelines to focus on these infections.

In summary, the study provides information that would be useful in reviewing and redirecting many programs in the region that have adopted or are planning to adopt the integrated approach for providing RTI and family planning services. 


\section{REFERENCE AND NOTES}

1 Plummer FJ, Simonsen D Cameron et al. (1991). "Co-factors in male- female sexual transmission of Human Immunodeficiency Virus Type 1" Journal of Infectious Diseases, 163:233-239.

2Laga M, (1992). “ Human Immunodeficiency Virus Prevention: The need for Complementary Sexually Transmitted Disease Control", pp 131-144 in Germain A, Holmes K, Piot P and Wasserheit J (Eds) Reproductive Tract Infections: Global Impact and Priorities for Women's Reproductive Health. Plenum Press New York, NY USA.

${ }^{3}$ Hunter D, Maggwa BN, Mati J., et al. (1994). "Sexual Behavior, Sexually Transmitted Diseases, Male Circumcision and Risk of HIV infection among women in Nairobi, Kenya", AIDS, 8:93-99.

4Kapiga S, Shao J, Lwihula G and Hunter D (1994). "Risk factors for HIV among women in Dar Es Salam, Tanzania", Journal of Acquired Immune Deficiency Syndrome, 7:301-309.

5 The National AIDS Coordination Program, Ministry of Health and Child Welfare, 1997. HIV/ AIDS in Zimbabwe: Background, Projections, Impact and Interventions, Harare, Zimbabwe.

6 Daly C, Maggwa BN, Mati J et al. (1994). " Risk factors for gonorrhea, syphilis and trichomoniasis infection among women attending family planning clinics in Nairobi, Kenya”. Genitourinary Medicine, 70: 155-161.

7 Tammerman M, Ali F, Achola et al. (1992). " Rapid increase in both HIV 1 infection and syphilis among pregnant women in Nairobi, Kenya", AIDS, 6:1181-1185

$8^{8}$ Gray R and Waweru M (1996). "Clinical/ laboratory methods for the diagnosis of reproductive morbidity in population-based studies", Seminar on innovative Approaches to the assessment of Reproductive Health, IUSSP Committee on Reproductive Health and Population Institute, University of the Philippines IUSSP, Liege, Belgium.

${ }^{9}$ Gerting D, Kapiga S, Shao J and Hunter D (1997). “ Risk factors for sexually transmitted diseases among women attending family planning clinics in Dar es Salam, Tanzania", Genitourinary Medicine, 70:39-43.

10 Wasserheit J and Holmes K (1992). "Reproductive tract infections: Challenges for international health policy, program and research", in Germain A, Holmes K, Piot P and Wasserheit J (eds), Reproductive Tract Infections: Global Impact and Priorities for Women's Reproductive Health. Plenum Press, New York NY, USA. 
${ }^{11}$ National DHS surveys, Botswana (1988), Kenya (1993), Uganda (1995), Tanzania (1996) Zambia (1996) and Zimbabwe (1994).

12 This methodology is based on the Population Council's Situation Analysis approach and requires a team of two researchers spending one week at a sample of clinics collecting data through a number of data collection instruments, including observations of client-provider interactions, exit interviews with clients and in-depth interviews with service providers, and a clinic inventory. It also requires in-depth interviews with senior program managers and policy makers and a review of policy and service delivery guideline documents

13 Valdez J., et al, (1997) "Assessing family planning service delivery skills in Kenya". Studies in family Planning, 28,2:143-150, 1997.

14 For staff, clinics and clients, the performance, readiness and satisfaction were considered satisfactory or to be of an acceptable quality if the number of failures on each indicator did not exceed an appropriate number called the Lot Tolerance Number of Failures (LTNF), or equivalent if the number of passes equals or exceeds an appropriate threshold value. The LTNF varies with the sample size being considered. For example, a provider examining say ten clients, on a given indicator such as whether or not a provider undertakes pelvic examination, would pass on this indicator if she performed the examination to at least eight clients or equivalently if she did not do so in at most two cases. In all cases a consumer or client's risk of $=0.10$ was used to determine the critical values upon which a decision about the quality of service may be based

15 According to the service provider guidelines, a complete pelvic exam should include; explaining to the clients the procedure in advance, asking the clients to pass urine before the exam, putting the client in the lithotomy position for the exam, inspecting the thighs, pubic and external genitalia for ulcers, separating the labia for proper inspection, speculum examination, bimanual examination and collection of a specimen for pap smear from all new, restarting and clients attending for annual check-up.

16 Latif A.S. (1997). “ Syndromic Management of Sexually Transmitted Diseases: Training Manual for STD Case Management". National AIDS Coordination Program, Ministry of Health and Child Welfare, Harare, Zimbabwe.

17 Clients were recruited into the study if they were above 16 years of age and had visited the clinic for any of the services in Table 2 and consented to participate in the study. All new family planning clients, clients attending for annual check-up, clients with problems with a current method, those with symptoms of RTIs and clients attending for infertility services were approached and requested to participate in the study. A random sample of clients attending for re-supply of methods were also recruited into the study.

18 Latif A.S (1997) op.cit. 
19 Cervicitis was defined as the presence of gonorrhea and/or Chlamydia infection confirmed by lab test.

20 Vaginitis was defined as the presence of Trichomoniais and/or Candida and/or Bacterial Vaginosis on lab test.

21 Kennedy GM, Neumann SM, et al (1995). 'Can we eradicate syphilis in pregnant women and newborns? Should we try?'. Reproductive Health Matters, No. 6, November 1995.

22 Dr. Mbegeranwa, Director Harare City Health Department. Paper presented at data interpretation workshop for this project. Harare, April 1999.

23 Miler K., Miller R., and Askew I. (Eds) (1997). “Clinic-Based Family Planning and Reproductive Health Services in Africa. Africa OR/TA project II, Population Council, New York, USA.

24 Sensitivity: The sensitivity is defined as the probability of clients having the symptoms and/or signs when they have a positive laboratory test for RTIs. For this study two major groups of RTIs are considered. Clients who have a positive laboratory test for Gonorrhea and/or Chlamydia are said to have cervical infections while those with Trichomoniasis, Candida and/or Bacterial Vaginosis are said to have vaginal infections.

25 Specificity: Specificity is defined as the probability of clients not having symptoms and/or signs when they test negative for RTIs on laboratory testing. This was measured by the proportion of clients who did not have symptoms and/ or signs when only those clients with a negative laboratory test are considered.

26 Positive predictive value (PPV): The PPV is defined as the probability of clients having a positive laboratory test when they have symptoms and/or signs. This probability is measured by the proportion of clients who have both a positive laboratory test and symptoms/or signs considering only those clients with symptoms and/or signs.

27 True Positive: This is a case that is diagnosed as infected when in fact the woman is infected.

False Positive: This is a case that is diagnosed as infected when in fact the woman is not infected. (These are the "over-treated" cases).

False Negative: This is a case that is diagnosed as uninfected when in fact the woman is infected. (These are the missed cases).

True Negative: This is a case that is diagnosed as uninfected when in fact the woman is uninfected.

28 Latif A.S. (1997) op. Cit. 
29 The standardized regression coefficient is a useful measure for comparing the predictive values of several independent variables in one model. The standard regression coefficient represents the predicted increase in the standard deviation units of the dependant variable that would be expected per standard deviation increase in the independent variable. By expressing changes in standard deviation units for the different independent variables it is possible to control for differences in the units of measurements for the independent variables and therefore make direct comparisons of their ability to predict the dependent variable. Rosner B. in Fundamentals in Biostatics, Third Edition, PWS-Kent Publishing Company. Boston, Massachusetts, USA 1990.

30 Marangwanda C., Kwaramba P., Janowitz B, et al. (1999). "The cost of integrating syndromic management for STIs into Zimbabwe's family planning program". Africa OR/TA Project II. Population Council, Nairobi, Kenya.

31 Latif AS (1997) op.cit.

32 Latif AS (1997) op.cit.

33 The incremental cost-effectiveness ratio is computed as:

(Cost of More Costly Algorithm - Cost of Least Costly Algorithm) / (Effectiveness of More Costly Algorithm - Effectiveness of Least Costly Algorithm)

34 This figure is estimated as $6.2 \%$ of gross domestic product per capita (the ratio reported in the World Development Report, 1993). 